$\begin{gathered}\text { EPiC Series in Education Science } \\ \text { Volume 1, 2017, Pages 1-9 }\end{gathered}$
$\begin{gathered}\text { AUBEA 2017: Australasian Universities Build- } \\ \text { ing Education Association Conference 2017 }\end{gathered}$

\title{
Resetting the Compass: An Immersive Intervention to Develop Abilities in Construction Management
}

\author{
John Smallwood ${ }^{1}$ and Christopher Allen ${ }^{1}$ \\ ${ }^{1}$ Nelson Mandela University, Port Elizabeth, South Africa \\ john.smallwood@mandela.ac.za, chris.allen@mandela.ac.za
}

\begin{abstract}
Students' post-intervention perceptions of an event provide insight relative to their understanding and appreciation of the intervention, as well as the impact thereof.

Experience and anecdotal evidence indicate that Honours students experience challenges in terms of completing the academic year.

The purpose of the study reported on is to determine the impact of a one-day team building event on participants directed at, inter alia, developing their ability to manage themselves, work as a team, and interface with each other, and their ability to strategise, plan, evolve tactics, and take action, based upon a self-administered questionnaire survey conducted in a South African university. The students were surveyed after the completion of the event.

The salient findings include - the team building activities impacted on participants in many ways, contributed to an enhancement of their ability to strategise, plan, evolve tactics, and take action, and participants enjoyed and benefited from the team building activities.

It can be concluded that the one-day team building event had the desired impact in terms of the development of participants' ability to manage themselves, work as a team, and interface with each other, and their ability to strategise, plan, evolve tactics, and take action.

It is recommended that the one-day team building event continue to be staged at the beginning of the Honours year, and that the post-event research be conducted on an annual basis.
\end{abstract}

Keywords: actions, construction management, students, survey, team building. 


\section{Introduction}

The traditional academic programme within the Nelson Mandela Metropolitan University (NMMU) Department of Construction Management has in recent years struggled to actively engage with students to prepare them adequately for the rigours of the honours year of study. An inability to manage themselves, strategise, plan, evolve tactics, and take action, which in turn should have contributed to their ability to study, undertake assignments, projects, and especially complete the treatise research project, have negatively impacted on the successful completion of the honours year of study.

Furthermore, these skills and attributes should have contributed to their ability to respond during employment interviews, effectively integrating them into the construction industry upon employment, and to fulfil a form of management function in the industry, which from industry liaison interaction was seen to be a weakness in the graduates being produced.

Given the aforementioned, and the Department of Construction Management's focus on 'lecturing and learning' research in addition to general assessment of courses, programmes, and related interventions, a survey was conducted among participants of a one-day team building event which was introduced at the commencement of the Honours year of study. The objective was to determine the impact on their ability to:

- manage themselves, work as a team, and interface with each other, and;

- $\quad$ strategise, plan, evolve tactics, and take action that would lead to their team winning the 'race'.

The aim of the research being to better prepare the students for the challenges of the Honours curriculum, specifically the intensity of the treatise research, as well as for workplace placement upon graduation.

\section{The Literature}

"Construction management programmes need to empower graduates to manage the business of construction" (Smallwood, 2006), which requires that the learning environment develop their ability to manage themselves, work as a team, and interface with each other. In addition, their ability to strategise, plan, evolve tactics, and take action, thus becomes a critical learning practice that will manifest itself in the ability to perform in the workplace, a necessity particularly within the African construction sector, where skills are in short supply.

Many authors argue that by advocating the systematic application of theory and techniques to every situation, traditional approaches to management education fail to consider that practitioners deal with ill-defined, unique, emotive, and complex issues (Cunliffe, 1999). This is the very essence of the challenges that students face in their honours year when competing deadlines will test their ability to manage their time and themselves to achieve an effective outcome across all subjects. However, this only introduces the theoretical challenges of the discipline and not the practices as experienced in the field. As Hmelo-Silver et al. (2007) state: "learning the concepts and theories of a discipline is best situated in the context of the practices of that discipline".

This exposes traditional pedagogy and teaching to critical questioning, with the focus on intellectual critiques not helping students to cope with everyday realities, responding, and learning that are the essence of practice (Cunliffe, 1999). Experience and anecdotal evidence indicate that honours students experience challenges in terms of completing the academic year and that this manifests itself in mediocre performance when entering the workplace. "Students learn content, strategies, and selfdirected learning skills through collaboratively solving problems" (Hmelo-Silver et al., 2007), so creating a learning environment in which students explore practices that increase interface time with 
one another, and explore other boundaries outside the current teaching and learning environment thus providing opportunities to tackle these deficiencies. This is in addition to students attempting to gain experience through vacation work which is undermined by a lack of practical skills.

Mo et al. (2007) emphasise that skills include an ability to think across disciplines, team working, and social and environmental awareness. Learning this in the traditional class room environment is challenging, not least due to students being unable to articulate their thoughts, nor communicate with their lecturers or one another, and an overreliance on smart phones as the only source of information coupled with an inability to read and discuss the findings of their investigations with their peers. To be effective in the workplace, and in their personal lives, students must be able to solve problems to make effective decisions; therefore, they must be able to think critically (Snyder \& Snyder, 2008). The Critical Thinking Community defined critical thinking as "the intellectually disciplined process of actively and skilfully conceptualising, applying, analysing, synthesising, and / or evaluating information gathered from, or generated by, observation, experience, reflection, reasoning, or communication, as a guide to belief and action." (Scriven \& Paul, 2007)

Jackson (2015) states that "it is important to be refining, developing and practicing your skills, not simply starting to learn them", which further emphasises the need to get students out of the classroom and into a pseudo work environment. There is an idea that all millennial students need active learning (Farrow, 2016) as they have become less exposed to workplace environments and participation in physical labour activities. Furthermore, the dramatic changes in social, economic, and environmental issues experienced since the turn of the millennium has forced construction management programmes to produce more prepared personnel (Lee et al., 2011). Simply put, students who can think critically are able to solve problems effectively. Merely having knowledge or information is not enough (Snyder \& Snyder, 2008).

When addressing inadequacies of both students and programmes, it is important to understand what it is they are expected to deliver when they enter the workplace. The nine recognised functions in an organisation, and five functions of management work, provide further insight relative to the knowledge and skills required by construction managers (Smallwood, 2006). By enhancing these through the types of activities included in a team-building event, construction management programmes are improving graduates' suitability for appropriate employment. In addition, as ESECT (Enhancing Student Employability Co-ordination Team) argued, to enhance employability, it is necessary to ensure that practices that foster understanding, skills, efficacy beliefs and metacognition (appropriate personal manner) are employed in higher education programmes (Yorke \& Knight, 2007).

Competency embodies the capacity to transfer skills and abilities from one area to another, and competencies are the characteristics of managers that lead to the demonstration of skills and abilities (Smallwood \& Emuze, 2011). An inability to sufficiently master these competencies whilst within the higher education domain through vacation work or practical skills learning, leaves the student ill prepared when they do finally graduate, as competent practitioners often rely on a tacit knowing-inaction to help them act within circumstances (Polanyi, 1966 quoted by Cunliffe, 1999).

In terms of the contribution of core competencies to project success, it can be concluded that motives are a major contributor at operational and top management level. Affect Control Theory (ACT) encompasses attitudes referred to as sentiments, motivations and impressions (Francis, 2011), all as determinants of attitudes, core variables of the theory and defined as "the persistent culturally-grounded affective meaning of an entity that serves as a reference for individual experience." (Heise, 2002) Furthermore, the ACT model proposes behaviour is influenced in a process of intuitive references made to fundamental attitudes as a basis for behaviour in social interactions (Francis, 2011).

In addressing specific core competencies, based upon their contribution to project success relative to their importance, it can be concluded that aptitude, attitude, team player, focus are critical core competencies to client success (Smallwood \& Emuze, 2011). Envisaging an environment outside the classroom with a unique set of physical and mental challenges to enhance these competencies becomes a strategy whereby construction management students are introduced to a collaborative problem-solving 
environment. This, whilst also enhancing their ability to strategise, plan, evolve tactics, and take action within a practical environment in which actions result in consequences for them and team mates, a pseudo project environment.

\section{Research}

\subsection{Research method and sample stratum}

Given the challenges recorded in the introduction, a team building event involving the honours students was undertaken on a Saturday at a resort near to the university. The event entailed five activities, namely traversing a zip line, negotiating an obstacle course, assembling a puzzle without a reference in the form of a complete view thereof, target shooting, and ejecting a plastic ball from a holed-tube filled with water. Each of the activities was entailed one or more of the following: strategising; planning; evolving of tactics, and taking of action.

Nineteen students, which could attend the team building event, were requested to complete a selfadministered questionnaire within a few days after the event. All nineteen responded. The questionnaire consisted of thirteen questions, twelve of which were closed ended, and either a five-point or six-point Likert scale type question. Only the findings relative to nine of the questions are reported on due to paper length constraints. A measure of central tendency in the form of a mean score (MS) between 1.00 and 5.00 (five-point), and 0.00 and 5.00 (six-point) was computed based upon the percentage responses to the points on the respective scales to enable interpretation of the responses and to rank variables where necessary. The responses were weighted as per the figures recorded within parentheses: did not (0); minor extent (1); near minor extent (2); some extent (3); near major extent (4); major extent (5).

\subsection{Research findings}

Table 1 indicates the extent to which the team building activities impacted on participants in terms of percentage responses to a scale of 1 (minor) to 5 (major) with an additional point 'did not'. Given that there are effectively six points on the scale, the MSs are between 0.00 and 5.00, the midpoint being 2.50. It is notable that all the MSs are $>2.50$, which indicates that in general the team building activities impacted more of a major than a minor extent on participants. However, a review of the MSs in terms of ranges provides a more detailed perspective. $2 / 7(28.6 \%) \mathrm{MSs}>4.17 \leq 5.00$, which indicates that the impact can be deemed to be between a near major extent to a major extent / major extent: your ability to communicate with your Honours colleagues, and removing you from your 'comfort zone'. The other $5 / 7$ (71.4\%) MSs are $>3.34 \leq 4.17$, which indicates the impact can be deemed to be between some extent to a near major extent / near major extent: building confidence in your own abilities; your ability to complete a task; enhancing alternative thought processes; your ability to be creative, and improving your time management skills. 


\begin{tabular}{|c|c|c|c|c|c|c|c|c|c|}
\hline \multirow{3}{*}{ Impact } & \multicolumn{7}{|c|}{ Response (\%) } & \multirow{3}{*}{ MS } & \multirow{3}{*}{ Rank } \\
\hline & \multirow{2}{*}{$\mathrm{U}$} & \multirow{2}{*}{$\begin{array}{l}\text { Did } \\
\text { not }\end{array}$} & \multicolumn{2}{|c|}{ Minor .... } & \multirow[b]{2}{*}{3} & \multirow{2}{*}{\multicolumn{2}{|c|}{$\frac{\text { Major }}{5}$}} & & \\
\hline & & & 1 & 2 & & & & & \\
\hline $\begin{array}{l}\text { Your ability to communicate } \\
\text { with your Honours colleagues }\end{array}$ & 0.0 & 5.3 & 0.0 & 0.0 & 0.0 & 21.1 & 73.7 & 4.53 & 1 \\
\hline $\begin{array}{l}\text { Removing you from your } \\
\text { 'comfort zone' }\end{array}$ & 0.0 & 0.0 & 10.5 & 0.0 & 0.0 & 36.8 & 52.6 & 4.21 & 2 \\
\hline $\begin{array}{l}\text { Building confidence in your } \\
\text { own abilities }\end{array}$ & 0.0 & 0.0 & 5.3 & 0.0 & 21.1 & 26.3 & 47.4 & 4.11 & 3 \\
\hline Your ability to complete a task & 0.0 & 0.0 & 10.5 & 0.0 & 10.5 & 26.3 & 52.6 & 4.11 & 4 \\
\hline $\begin{array}{l}\text { Enhancing alternative thought } \\
\text { processes }\end{array}$ & 0.0 & 0.0 & 5.3 & 5.3 & 10.5 & 36.8 & 42.1 & 4.05 & 5 \\
\hline Your ability to be creative & 0.0 & 11.1 & 5.6 & 0.0 & 11.1 & 22.2 & 50.0 & 3.78 & 6 \\
\hline $\begin{array}{l}\text { Improving your time } \\
\text { management skills }\end{array}$ & 0.0 & 5.3 & 5.3 & 0.0 & 15.8 & 47.4 & 26.3 & 3.74 & 7 \\
\hline
\end{tabular}

Table 1: Extent to which the team building activities impacted on participants

Table 2 indicates the extent to which the team building activities enhanced participants' various abilities in terms of percentage responses to a scale of 1 (minor) to 5 (major), an additional point 'did not', and MSs. It is notable that all the MSs are $>2.50$, which indicates that in general the team building activities enhanced participants' various abilities more of a major than a minor extent. 3 / 4 (75\%) MSs $>4.17 \leq 5.00$, which indicates that the enhancement can be deemed to be between a near major extent to a major extent / major extent: strategise, evolve tactics, and take action. The MS relative to plan is $>$ $3.34 \leq 4.17$, which indicates the enhancement can be deemed to be between some extent to a near major extent / near major extent.

\begin{tabular}{|c|c|c|c|c|c|c|c|c|c|}
\hline \multirow{3}{*}{ Ability } & \multicolumn{7}{|c|}{ Response (\%) } & \multirow{3}{*}{ MS } & \multirow{3}{*}{ Rank } \\
\hline & \multirow{2}{*}{$\mathrm{U}$} & \multirow{2}{*}{$\begin{array}{l}\text { Did } \\
\text { not }\end{array}$} & \multicolumn{2}{|c|}{ Minor ... } & & \multicolumn{2}{|c|}{.....Major } & & \\
\hline & & & 1 & 2 & 3 & 4 & 5 & & \\
\hline Strategise & 0.0 & 0.0 & 0.0 & 0.0 & 10.5 & 31.6 & 57.9 & 4.47 & 1 \\
\hline Evolve tactics & 0.0 & 0.0 & 0.0 & 5.3 & 10.5 & 31.6 & 52.6 & 4.32 & 2 \\
\hline Take action & 0.0 & 0.0 & 0.0 & 5.3 & 15.8 & 26.3 & 52.6 & 4.26 & 3 \\
\hline Plan & 0.0 & 5.3 & 0.0 & 5.3 & 10.5 & 26.3 & 52.6 & 4.11 & 4 \\
\hline
\end{tabular}

Table 2: Extent to which the team building activities enhanced participants' various abilities

Respondents were then required to indicate the extent to which the individual team building activities enhanced participants' ability to strategise, evolve tactics, take action, and plan relative to each activity.

Table 3 indicates thus relative to the ability to strategise. It is notable that 4 / $5(80 \%)$ of the MSs are $>3.00$, which indicates that in general the team building activities enhanced participants' ability to strategise to a major as opposed to a minor extent. $3 / 5(60 \%)$ MSs $>4.20 \leq 5.00$, which indicates that the enhancement can be deemed to be between a near major extent to a major extent / major extent: puzzle; filling of tube, and obstacle course. The MS relative to shooting is $>3.40 \leq 4.20$, which indicates the enhancement can be deemed to be between some extent to a near major extent / near major extent. The MS relative to zip line is $>2.60 \leq 3.40$, which indicates the enhancement can be deemed to be between a near minor extent to some extent/ some extent. 


\begin{tabular}{|c|c|c|c|c|c|c|c|c|}
\hline \multirow{3}{*}{ Activity } & \multicolumn{6}{|c|}{ Response (\%) } & \multirow{3}{*}{ MS } & \multirow{3}{*}{ Rank } \\
\hline & \multirow{2}{*}{$\mathrm{U}$} & \multicolumn{2}{|c|}{ Minor ....... } & \multicolumn{3}{|c|}{..Major } & & \\
\hline & & 1 & 2 & 3 & 4 & 5 & & \\
\hline Puzzle & 0.0 & 0.0 & 0.0 & 5.3 & 21.1 & 73.7 & 4.68 & 1 \\
\hline Filling of tube & 0.0 & 0.0 & 0.0 & 10.5 & 21.1 & 68.4 & 4.58 & 2 \\
\hline Obstacle course & 0.0 & 0.0 & 0.0 & 0.0 & 47.4 & 52.6 & 4.53 & 3 \\
\hline Shooting & 0.0 & 5.3 & 26.3 & 5.3 & 26.3 & 36.8 & 3.63 & 4 \\
\hline Zip line & 5.6 & 22.2 & 16.7 & 16.7 & 11.1 & 27.8 & 2.89 & 5 \\
\hline
\end{tabular}

Table 3: Extent to which the team building activities enhanced participants' ability to strategise

Table 4 indicates the extent to which the team building activities enhanced participants' ability to plan. It is notable that $3 / 5(60 \%)$ of the MSs are $>3.00$, which indicates that in general the team building activities enhanced participants' ability to plan to a major as opposed to a minor extent. 2 / 5 (40\%) MSs $>4.20 \leq 5.00$, which indicates that the enhancement can be deemed to be between a near major extent to a major extent / major extent: puzzle, and obstacle course. The MS relative to filling of tube is $>3.40 \leq 4.20$, which indicates the enhancement can be deemed to be between some extent to a near major extent / near major extent. The MS relative to shooting is $>2.60 \leq 3.40$, which indicates the enhancement can be deemed to be between a near minor extent to some extent / some extent. Then, the MS relative to zip line is $>1.80 \leq 2.60$, which indicates the enhancement can be deemed to be between a minor extent to a near minor extent / near minor extent.

\begin{tabular}{|c|c|c|c|c|c|c|c|c|}
\hline \multirow{3}{*}{ Activity } & \multicolumn{6}{|c|}{ Response $(\%)$} & \multirow{3}{*}{ MS } & \multirow{3}{*}{ Rank } \\
\hline & \multirow{2}{*}{$\mathrm{U}$} & \multicolumn{5}{|c|}{ Minor ..................Major } & & \\
\hline & & 1 & 2 & 3 & 4 & 5 & & \\
\hline Puzzle & 0.0 & 0.0 & 5.3 & 5.3 & 36.8 & 52.6 & 4.37 & 1 \\
\hline Obstacle course & 0.0 & 0.0 & 5.3 & 5.3 & 47.4 & 42.1 & 4.26 & 2 \\
\hline Filling of tube & 5.3 & 0.0 & 5.3 & 5.3 & 36.8 & 47.4 & 4.11 & 3 \\
\hline Shooting & 5.3 & 10.5 & 26.3 & 26.3 & 10.5 & 21.1 & 2.89 & 4 \\
\hline Zip line & 5.3 & 31.6 & 15.8 & 26.3 & 10.5 & 10.5 & 2.37 & 5 \\
\hline
\end{tabular}

Table 4: Extent to which the team building activities enhanced participants' ability to plan

Table 5 indicates the extent to which the team building activities enhanced participants' ability to evolve tactics. It is notable that $3 / 5(60 \%)$ of the MSs are $>3.00$, which indicates that in general the team building activities enhanced participants' ability to evolve tactics to a major as opposed to a minor extent. 3 / $5(60 \%)$ MSs $>4.20 \leq 5.00$, which indicates that the enhancement can be deemed to be between a near major extent to a major extent / major extent: puzzle; filling of tube, and obstacle course. The MS relative to shooting is $>2.60 \leq 3.40$, which indicates the enhancement can be deemed to be between a near minor extent to some extent / some extent. Then, the MS relative to zip line is $>1.80 \leq$ 2.60 , which indicates the enhancement can be deemed to be between a minor extent to a near minor extent / near minor extent. 


\begin{tabular}{|c|c|c|c|c|c|c|c|c|}
\hline \multirow{3}{*}{ Activity } & \multicolumn{6}{|c|}{ Response (\%) } & \multirow{3}{*}{ MS } & \multirow{3}{*}{ Rank } \\
\hline & \multirow{2}{*}{$\mathrm{U}$} & \multicolumn{2}{|c|}{ Minor ....... } & \multicolumn{3}{|c|}{.....Major } & & \\
\hline & & 1 & 2 & 3 & 4 & 5 & & \\
\hline Puzzle & 0.0 & 0.0 & 0.0 & 5.3 & 42.1 & 52.6 & 4.47 & 1 \\
\hline Filling of tube & 0.0 & 5.3 & 0.0 & 5.3 & 42.1 & 47.4 & 4.26 & 2 \\
\hline Obstacle course & 0.0 & 0.0 & 0.0 & 15.8 & 47.4 & 36.8 & 4.21 & 3 \\
\hline Shooting & 5.3 & 5.3 & 31.6 & 15.8 & 26.3 & 15.8 & 3.00 & 4 \\
\hline Zip line & 5.6 & 33.3 & 22.2 & 11.1 & 16.7 & 11.1 & 2.33 & 5 \\
\hline
\end{tabular}

Table 5: Extent to which the team building activities enhanced participants' ability to evolve tactics

Table 6 indicates the extent to which the team building activities enhanced participants' ability to take action. It is notable that all the MSs are $>3.00$, which indicates that in general the team building activities enhanced participants' ability to take action to a major as opposed to a minor extent. 2 / 5 $(40 \%)$ MSs $>4.20 \leq 5.00$, which indicates that the enhancement can be deemed to be between a near major extent to a major extent / major extent: filling of tube, and obstacle course. The MSs relative to puzzle, zip line, and shooting are $>3.40 \leq 4.20$, which indicates the enhancement can be deemed to be between some extent to a near major extent / near major extent.

\begin{tabular}{|c|c|c|c|c|c|c|c|c|}
\hline \multirow{3}{*}{ Activity } & \multicolumn{6}{|c|}{ Response (\%) } & \multirow{3}{*}{ MS } & \multirow{3}{*}{ Rank } \\
\hline & \multirow{2}{*}{$\mathrm{U}$} & \multicolumn{2}{|c|}{ Minor ...... } & \multicolumn{3}{|c|}{....Major } & & \\
\hline & & 1 & 2 & 3 & 4 & 5 & & \\
\hline Filling of tube & 0.0 & 0.0 & 5.3 & 5.3 & 36.8 & 52.6 & 4.37 & 1 \\
\hline Obstacle course & 0.0 & 0.0 & 5.3 & 5.3 & 47.4 & 42.1 & 4.26 & 2 \\
\hline Puzzle & 5.3 & 0.0 & 0.0 & 15.8 & 36.8 & 42.1 & 4.05 & 3 \\
\hline Zip line & 0.0 & 10.5 & 10.5 & 21.1 & 31.6 & 26.3 & 3.53 & 4 \\
\hline Shooting & 5.3 & 5.3 & 15.8 & 15.8 & 21.1 & 36.8 & 3.53 & 5 \\
\hline
\end{tabular}

Table 6: Extent to which the team building activities enhanced participants' ability to take action

Table 7 provides a summary of the extent to which all the activities enhanced the four abilities of participants based upon the extent to which the individual team building activities enhanced participants' ability to strategise, evolve tactics, take action, and plan, in terms of MSs and ranks. In terms of the enhancement of all four abilities, puzzle (MS $=4.39)$ was ranked first, followed closely by filling of tube ( $\mathrm{MS}=4.33$ ), and obstacle course ( $\mathrm{MS}=4.32)$. The aforementioned were the team building activities, and required a strategy, plan, the evolution of tactics, and team action. Their mean MSs $>4.20 \leq 5.00$, which indicates that the enhancement can be deemed to be between a near major extent to a major extent / major extent. They were followed by shooting (MS = 3.26), and zip line (MS = 2.78). Then, in terms of the mean MS / ability, strategise (MS = 4.06) is ranked first, followed by take action ( $\mathrm{MS}=3.95)$, evolve tactics ( $\mathrm{MS}=3.65)$, and plan (MS =3.60). It is notable that these mean MSs are all lower than the MSs relative to the extent to which the team building activities enhanced participants' various abilities (Table 2). Then, in the case of the latter, strategise (MS $=4.47$ ) was ranked first, followed by evolve tactics (MS = 4.32), take action (4.26), and plan (4.11). 


\begin{tabular}{lcccccccccc}
\hline \multirow{2}{*}{ Activity } & \multicolumn{10}{c}{ Ability } \\
\cline { 2 - 14 } & \multicolumn{2}{c}{ Strategise } & \multicolumn{2}{c}{ Plan } & \multicolumn{2}{c}{$\begin{array}{c}\text { Evolve } \\
\text { tactics }\end{array}$} & Take action & \multicolumn{2}{c}{ Mean } \\
\cline { 2 - 13 } & MS & Rank & MS & Rank & MS & Rank & MS & Rank & MS & Rank \\
\hline Zip line & 2.89 & 5 & 2.37 & 5 & 2.33 & 5 & 3.53 & 4 & 2.78 & 5 \\
\hline Obstacle course & 4.53 & 3 & 4.26 & 2 & 4.21 & 3 & 4.26 & 2 & 4.32 & 3 \\
\hline Puzzle & 4.68 & 1 & 4.37 & 1 & 4.47 & 1 & 4.05 & 3 & 4.39 & 1 \\
\hline Shooting & 3.63 & 4 & 2.89 & 4 & 3.00 & 4 & 3.53 & 5 & 3.26 & 4 \\
\hline Filling of tube & 4.58 & 2 & 4.11 & 3 & 4.26 & 2 & 4.37 & 1 & 4.33 & 2 \\
\hline Mean / Ability & 4.06 & 1 & 3.60 & 4 & 3.65 & 3 & 3.95 & 2 & 3.82 & \\
\hline
\end{tabular}

Table 7: Summary of the extent to which all the activities enhanced the four abilities of participants

Respondents were required to indicate the extent to which they enjoyed and benefited from the team building activities. Both MSs > $4.17 \leq 5.00$ - enjoy $(\mathrm{MS}=4.79)$, and benefit from $(\mathrm{MS}=4.63)$, which indicates that the enjoyment and benefit can be deemed to be between a near major extent to a major extent / major extent.

Table 8 indicates the extent to which participants benefited from the team building activities. It is notable all the MSs are $>3.00$, which indicates that in general the participants benefited from the team building activities to a major as opposed to a minor extent. 3 / 5 (60\%) MSs $>4.20 \leq 5.00$, which indicates that the benefit can be deemed to be between a near major extent to a major extent / major extent: puzzle; filling of tube, and obstacle course. The MSs relative to zip line and shooting are $>3.40$ $\leq 4.20$, which indicates the benefit can be deemed to be between some extent to a near major extent / near major extent.

\begin{tabular}{|c|c|c|c|c|c|c|c|c|}
\hline \multirow{3}{*}{ Activity } & \multicolumn{6}{|c|}{ Response $(\%)$} & \multirow{3}{*}{ MS } & \multirow{3}{*}{ Rank } \\
\hline & \multirow{2}{*}{$\mathrm{U}$} & \multicolumn{2}{|c|}{ Minor ....... } & \multicolumn{3}{|c|}{......Major } & & \\
\hline & & 1 & 2 & 3 & 4 & 5 & & \\
\hline Puzzle & 0.0 & 0.0 & 0.0 & 15.8 & 21.1 & 63.2 & 4.47 & 1 \\
\hline Filling of tube & 0.0 & 0.0 & 10.5 & 5.3 & 26.3 & 57.9 & 4.32 & 2 \\
\hline Obstacle course & 0.0 & 5.3 & 0.0 & 15.8 & 26.3 & 52.6 & 4.21 & 3 \\
\hline Zip line & 0.0 & 5.3 & 5.3 & 31.6 & 15.8 & 42.1 & 3.84 & 4 \\
\hline Shooting & 0.0 & 15.8 & 10.5 & 5.3 & 21.1 & 47.4 & 3.74 & 5 \\
\hline
\end{tabular}

Table 8: Extent to which participants benefited from the team building activities

$10.5 \%$ of respondents did not make a comment and $89.5 \%$ made one comment, which equates to a mean of 0.89 comments per respondent. Selected comments include: "Awesome team building exercise, thoroughly enjoyed every activity which also allowed me to interact with my classmates"; "The event really enhanced my ability to communicate with my honours colleagues on a different level"; "Very beneficial as it brought honours class together, so we could tackle the year ahead as a team"; "Was an eye-opener emphasising on the importance of team building, achieving and setting goals as a team.", and "Not only honours student, but also lower grades should be introduced to the team building culture".

\section{Conclusions}

Non-traditional academic programme interventions such as the team building event reported on, do impact on honours' students' ability, to manage themselves, strategise, plan, evolve tactics, and take action, which in turn should contribute to their ability to study, undertake assignments, projects, and especially the treatise research project, and successfully complete the honours year of study. 
Furthermore, the impact should contribute to their ability to respond during employment interviews, effectively integrate into the construction industry upon employment, and to fulfil a form of management function in the industry. However, this can only be quantified post-graduation.

\section{Recommendations}

Recommendations include that the team building event be undertaken on an annual basis, but at first year level, that the impact thereof on participants be determined, and that further potential events directed at enhancing interpersonal skills, team building abilities, and the ability to strategise, plan, evolve tactics, and take action, be investigated.

\section{References}

Cunliffe, A. (1999) Critical Pedagogy: Reflexive dialogical practice in management learning, The Critical Management Studies (CMS) Conference, Downloaded from: https://www.mngt.waikato.ac.nz/ejrot/cmsconference/papers mgmteduc.htm

Farrow, C.B. (2016) Correlating learning styles and student experience in a construction field lab, In: Proceedings of the RICS COBRA 2016 conference, Toronto.

Francis, C.A. (2011). Student course evaluations: Association with pre-course attitudes and comparison of business courses in social science and quantitative topics, North American Journal of Psychology, Vol. 13(1), pp 141-154.

Heise, D.R. (2002). Understanding social interaction with affect control theory. In B.J. and M. Zelditch (Eds.). New directions in sociological theory. Boulder, CO: Rowman and Littlefield.

Hmelo-Silver, C., Duncan, R. and Chinn, C. (2007) Scaffolding and Achievement in Problem-Based and Inquiry Learning: A Response to Kirschner, Sweller, and Clark, Educational Psychologist, 42(2), pp 99-107.

Lee, N., Ponton, R., Jeffreys, A.W. and Cohn, R., 2011. Analysis of industry trends for improving undergraduate curriculum in construction management education. In: ASC Proceedings of the 47th Annual International Conference, Omaha, NE.

Mo, Y., Dainty, A. and Price, A. (2007) An assessment of the emotional intelligence of construction students: An empirical investigation, In: Proceedings of the 23rd Annual Conference of the Association of Researchers in Construction Management, 3-5 September 2007, Belfast, UK. Association of Researchers in Construction Management, 1, pp 325-34.

Smallwood, J.J. (2006) The Practice of Construction Management, Acta Structilia, 13(2), pp 62-89.

Smallwood, J.J. and Emuze, F. (2011) Core competencies and the practice of construction management: A pilot South African study, In: Proceedings of the $27^{\text {th }}$ Annual Conference of the Association of Researchers in Construction Management, 5-7 September 2011, Bristol, UK. Association of Researchers in Construction Management, pp 383-392.

Snyder, L.G. and Snyder, M.J., 2008. Teaching critical thinking and problem solving skills. The Journal of Research in Business Education, 50(2), pp 90.

Springer, K. (2010). Educational Research: A Contextual Approach, Hoboken: John Wiley \& Sons.

Yorke, M. and Knight, P. (2007) Evidence-informed pedagogy and the enhancement of student employability, Teaching in Higher Education, 12(2), pp 157-170. 